\title{
Recombination and positive selection identified in complete genome sequences of Japanese encephalitis virus
}

\author{
Jennifer Carney $\cdot$ Janet M. Daly $\cdot$ Ananda Nisalak • \\ Tom Solomon
}

Received: 27 July 2011/Accepted: 6 October 2011/Published online: 28 October 2011

(C) The Author(s) 2011. This article is published with open access at Springerlink.com

\begin{abstract}
The mosquito-borne Japanese encephalitis virus (JEV) causes encephalitis in man but not in pigs. Complete genomes of a human, mosquito and pig isolate from outbreaks in 1982 and 1985 in Thailand were sequenced with the aim of identifying determinants of virulence that may explain the differences in outcomes of JEV infection between pigs and man. Phylogenetic analysis revealed that five of these isolates belonged to genotype I, but the 1982 mosquito isolate belonged to genotype III. There was no evidence of recombination among the Thai isolates, but there were phylogenetic signals suggestive of recombination in a 1994 Korean isolate (K94P05). Two sites of the genome under positive selection were identified: codons 996 and 2296 (amino acids 175 of the nonstructural protein NS1 and 24 of NS4B, respectively). A structurally significant substitution was seen at NS4B position 24 of the human isolate compared with the mosquito and pig isolates from the 1985 outbreak in Thailand.
\end{abstract}

Electronic supplementary material The online version of this article (doi:10.1007/s00705-011-1143-4) contains supplementary material, which is available to authorized users.

J. Carney · J. M. Daly · T. Solomon

Brain Infections Group, Department of Clinical Infection, Microbiology and Immunology, Institute of Infection and Global Health, University of Liverpool, Liverpool L69 3GA, UK

J. M. Daly $(\bowtie)$

School of Veterinary Medicine and Science,

University of Nottingham, Sutton Bonington Campus,

Sutton Bonington, Leicestershire LE12 5RD, UK

e-mail: janet.daly@nottingham.ac.uk

A. Nisalak

Armed Forces Research Institute of Medical Sciences (AFRIMS), Bangkok, Thailand
The potential importance of the two sites in the evolution and ecology of JEV merits further investigation.

\section{Abbreviation \\ KPP Kamphaeng Phet Province}

\section{Introduction}

Japanese encephalitis virus (JEV) is a significant cause of epidemic encephalitis in people throughout Asia. The virus is a member of the Japanese encephalitis (JE) serogroup of the genus Flavivirus, family Flaviviridae, which also includes West Nile virus (WNV), St Louis encephalitis virus (SLEV) and dengue virus. These flaviviruses consist of a glycoprotein-containing lipid envelope surrounding a nucleocapsid, which encloses one molecule of singlestranded positive-sense RNA [2]. This 11-kb molecule comprises $5^{\prime}$ and $3^{\prime}$ untranslated regions (UTRs), between which a single open reading frame encodes seven nonstructural proteins (NS1, NS2a, NS2b, NS3, NS4a, NS4b and NS5) and three structural proteins: capsid (C); premembrane (prM); envelope (E).

It is thought that JEV evolved from an ancestral virus in the Indonesia-Malaysia region [30]. Based on nucleotide sequencing of the $\mathrm{C} / \mathrm{prM}$ and $\mathrm{E}$ genes, four genotypes of JEV have been identified; the complete genomes of representatives of each genotype have been sequenced. A single member of a putative fifth genotype has been identified [34]. No viruses belonging to genotype IV have been isolated outside the Indonesia-Malaysia region, whereas genotypes I to III have spread across Asia. Relatively recently, virus belonging to genotype II has encroached 
into the northern territories of Australia [12], and subsequently, genotype I viruses have appeared in the Australasian region [27]. Analysis of E gene sequences has previously identified five viruses as having recombinant sequences between genotypes I and III or III and IV [11, 33].

JEV is transmitted by mosquitoes, principally of the Culex species. Humans are incidental hosts that become infected when they encroach upon the natural cycle of the virus. Ardeid birds, including herons and egrets, act as reservoir hosts, but infection rates in man are higher in areas where pigs are kept; hence, pigs are regarded as 'amplifying hosts'. Only a proportion of people infected with JEV develop neurologic disease, and it is not a feature of infection in pigs. The factors governing the development of neurologic signs are poorly understood, but it is likely that both the host's innate immune responses and strain virulence determinants play a role [31].

The aim of this study was to analyze the genome of JEV for any indication of strain virulence determinants that might underlie the difference in outcome of infection in pigs on the one hand, and man on the other.

\section{Materials and methods}

\section{Viruses}

Two sets of three viruses (from a pig, human or mosquito) isolated during outbreaks in 1982 and 1985 in Kamphaeng Phet Province, Thailand, were selected because they had undergone limited passage in the laboratory (Table S1).

\section{RNA extraction, reverse transcription and PCR (RT-PCR)}

Viral RNA was extracted from $140 \mu \mathrm{l}$ of cell-free tissue culture supernatant using a QIAmp ${ }^{\circledR}$ Viral RNA Mini Kit (QIAGEN) according to the manufacturer's guidelines. Viral RNA ( $5 \mu \mathrm{l}), 10$ pmol antisense primer (Table S2) and $500 \mu \mathrm{M}$ each dNTP (Roche Applied Sciences) in a 12- $\mu 1$ volume were heated to $65^{\circ} \mathrm{C}$ for $5 \mathrm{~min}$ and immediately placed on ice. After chilling on ice, a master mix containing $4 \mu \mathrm{l}$ of $5 \mathrm{x}$ first-strand buffer, $10 \mathrm{mM}$ DTT and $40 \mathrm{U}$ ribonuclease inhibitor (all from Invitrogen) was added to each tube. Superscript I reverse transcriptase (200 U) was added after 2 min during incubation at $42^{\circ} \mathrm{C}$ for $65 \mathrm{~min}$, which was followed by incubation at $70^{\circ} \mathrm{C}$ for $5 \mathrm{~min}$. Finally, RNA was digested by incubation at $37^{\circ} \mathrm{C}$ for 20 min with 2 U RNase H (Invitrogen).

PCR was carried out with 3-8 $\mu$ cDNA template, 400 nM primers, $200 \mu \mathrm{M}$ each dNTP, $2.5 \mu \mathrm{l} 10 \mathrm{x}$ polymerase buffer and 0.5 U Taq DNA polymerase (Promega) in a
25- $\mu \mathrm{l}$ volume. After an initial denaturation step at $94^{\circ} \mathrm{C}$ for 5 min, cycling parameters (annealing temperature and time for extension and number of cycles) were varied with the primer set used. A final extension step of $72^{\circ} \mathrm{C}$ for $5 \mathrm{~min}$ was carried out. Products of amplification were evaluated by electrophoresis in a $1.5 \%$ agarose gel in $0.04 \mathrm{M}$ Tris/ acetate/0.001 M EDTA (TAE) buffer. DNA bands visualized by ethidium bromide staining and UV transillumination were excised from the agarose gel and purified using a QIAquick Gel Extraction Kit (QIAGEN).

\section{Sequencing}

Purified DNA products were ligated into the $\mathrm{pGEM}^{\circledR}-\mathrm{T}$ Easy vector (Promega), and ligated plasmids were introduced into DH5 $\alpha$ competent Escherichia coli through chemical transformation. Transformed cells were spread onto LB/ampicillin/IPTG/X-Gal plates and incubated overnight at $37^{\circ} \mathrm{C}$. Individual white colonies were used to inoculate $3 \mathrm{ml} \mathrm{LB}$ broth. After overnight incubation at $37^{\circ} \mathrm{C}$ with shaking, plasmid DNA was extracted from 1 to $2 \mathrm{ml}$ using a S.N.A.P. MiniPrep Kit (Invitrogen). To verify the presence of DNA inserts, extracted plasmid DNA was digested with EcoRI and examined by agarose gel electrophoresis.

Sequencing reactions were performed by Lark Technologies, Essex, UK, on an ABI 3130 Genetic Analyzer (Applied Biosystems). At least two independent plasmid preparations were sequenced using M13 forward and reverse primers. If there was disagreement between the two plasmids, a third was sequenced to obtain a consensus. All sequences were confirmed by direct sequencing of purified RT-PCR products using the virus-specific primers used for amplification.

Phylogenetic analysis

Complete genome sequences were obtained for the six JEV isolates from Kamphaeng Phet Province (KPP), Thailand, and aligned with complete genome sequences available on GenBank for which the year of isolation was known, excluding vaccine strains or other laboratory-derived mutant strains (Table 1). The sequences were aligned using Clustal W version 1.83 [5] and manually edited to obtain the codon region frame only. The general time-reversible (GTR) model with gamma distributed rate variation among sites was identified as the appropriate nucleotide substitution model for phylogenetic analysis using the Findmodel implementation of MODELTEST [26]. Phylogenetic trees were constructed using PAUP* v4.0b10 [32] and FigTree version 1.1 [28]. An initial phylogenetic tree to identify genotypes was constructed using neighbor-joining (NJ). The tree topology was confirmed using maximum- 
Table 1 Complete genome sequences included in phylogenetic analysis

\begin{tabular}{|c|c|c|c|c|}
\hline Strain & $\begin{array}{l}\text { Year of } \\
\text { isolation }\end{array}$ & Country & Species & $\begin{array}{l}\text { Accession } \\
\text { no. }\end{array}$ \\
\hline Nakayama & 1935 & Japan & Human & EF571853 \\
\hline Beijing-1 & 1949 & China & Human & L48961 \\
\hline P3 & 1949 & China & Mosquito & U47032 \\
\hline SA14 & 1954 & China & Mosquito & U14163 \\
\hline Vellore P20778 & 1958 & India & Human & AF080251 \\
\hline HVI & 1958 & Taiwan & Human & AF098735 \\
\hline JaGAr01 & 1959 & Japan & Mosquito & AF069076 \\
\hline Ling & 1965 & Taiwan & Human & L78128 \\
\hline $\mathrm{TL}$ & 1965 & Taiwan & Human & AF098737 \\
\hline $\mathrm{JaOH} 0566$ & 1966 & Japan & Human & AY508813 \\
\hline GP78 & 1978 & India & Human & AF075723 \\
\hline JKT-6468 & 1981 & Indonesia & Mosquito & AY184212 \\
\hline $\mathrm{JaOArS} 982$ & 1982 & Japan & Mosquito & M18370 \\
\hline КРP82-39-214CТ & 1982 & Thailand & Mosquito & GQ902063 ${ }^{\mathrm{a}}$ \\
\hline B0860/82 & 1982 & Thailand & Pig & GQ902058 \\
\hline 1070/82 (Subin) & 1982 & Thailand & Human & GQ902059 ${ }^{\mathrm{a}}$ \\
\hline 3KP'U'CV569 & 1985 & Thailand & Mosquito & GQ902060 \\
\hline B1381-85 & 1985 & Thailand & Pig & GQ902061 ${ }^{\mathrm{a}}$ \\
\hline $4790-85$ & 1985 & Thailand & Human & GQ902062 \\
\hline K87P39 & 1987 & Korea & Mosquito & AY585242 \\
\hline CH1392 & 1990 & Taiwan & Mosquito & AF254452 \\
\hline Ishikawa & 1994 & Japan & Pig & AB051292 \\
\hline К94P05 & 1994 & Korea & Mosquito & AF045551 \\
\hline FU & 1995 & Australia & Human & AF217620 \\
\hline T1P1 & 1997 & Taiwan & Mosquito & AF254453 \\
\hline KV1899 & 1999 & Korea & Pig & AY316157 \\
\hline $\begin{array}{c}\text { JEV/Sw/Mie/ } \\
41 / 2002\end{array}$ & 2002 & Japan & Pig & AB241119 \\
\hline $\begin{array}{c}\text { JEV/Sw/Mie/ } \\
40 / 2004\end{array}$ & 2004 & Japan & Pig & AB241118 \\
\hline
\end{tabular}

${ }^{\text {a }}$ Indicates complete genome sequences obtained as part of this study

likelihood with tree bisection-reconnection and nearestneighbor interchange perturbations. Bootstrap analysis (1000 replicates) was performed to assess the reliability of branches.

To identify any conflicting signals in the complete genome sequences that may indicate recombination, a phylogenetic network was constructed using SplitsTree 4 version 4.10 [13]. To confirm evidence of potential recombination, potential parental sequences were identified using RDP3 [21], and a similarity plot was generated using the Kimura two-parameter method in Simplot version 3.5.1 [19], applying a window size of $400 \mathrm{bp}$ and a step size of $50 \mathrm{bp}$.

Simplot was used to 'slice' alignments containing putative recombinant and non-recombinant strains representing the different genotypes at the identified breakpoints. Phylogenetic trees were constructed for the different segments of each recombinant using the NJ method, and bootstrap values for 1000 replicates were used to assess the support for clustering of segments with strains of different genotypes.

To determine the gene- and site-specific selection pressures acting on the JEV genome, three different codonbased maximum-likelihood methods, SLAC, FEL and REL within the HYPHY software package as implemented in Datamonkey (www.datamonkey.org) with significance levels set at $\mathrm{p}=0.1, \mathrm{p}=0.1$ and Bayes factor $=50$, respectively, were used to estimate the rate of nonsynonymous $(d N)$ and synonymous $(d S)$ substitutions at each codon site.

\section{Results}

Viruses from different genotypes co-circulated in Kamphaeng Phet Province, Thailand in 1982

The reconstructed phylogeny showed that five of the six isolates from KPP, Thailand, belonged to genotype I, but the mosquito isolate from 1982 (KPP82-39-214CT) belonged to genotype III (Fig. 1). This resulted in only one set of isolates being available for comparison of the genomes of viruses isolated from the three different species (mosquito, man and pig) during the same outbreak.

There were 15 amino acid differences among the 1985 mosquito, pig and human isolate sequences (Table 2). The mosquito isolate was distinct at three amino acid positions, the pig isolate at five, and the 1985 human isolate was distinct from the pig and mosquito isolates at seven amino acid positions. Two of the seven changes in the human isolate were non-conservative ( $\mathrm{P} 24 \mathrm{~S}$ in the NS4B protein and A97T in the NS2A protein). The $5^{\prime}$ UTR sequences were identical, but there were nine nucleotide differences among the $3^{\prime}$ UTR sequences: four unique to the isolate from a pig (10406: $\mathrm{T} \rightarrow \mathrm{C}$, 10419: $\mathrm{C} \rightarrow \mathrm{T}$, 10426: $\mathrm{A} \rightarrow \mathrm{G}$, 10560: $\mathrm{G} \rightarrow \mathrm{A}$ ), three unique to mosquito (10559: $A \rightarrow G, 10675: T \rightarrow C, 10775:$ $\mathrm{C} \rightarrow \mathrm{T}$ ) and two unique to the human isolate (10686: $\mathrm{T} \rightarrow \mathrm{C}$, 10786: $A \rightarrow G)$. None of these lie in the structural elements identified by Olsthoorn and Bol [25].

There were three amino acid substitutions between the pig and human isolates from the 1982 outbreak: A122T in the capsid protein, G306E in the envelope protein, and G354E in NS3. There were no substitutions in the untranslated regions.

Korean isolate identified as a recombinant

The co-circulation of two distinct genotypes during the same year in the same region suggested that the conditions 


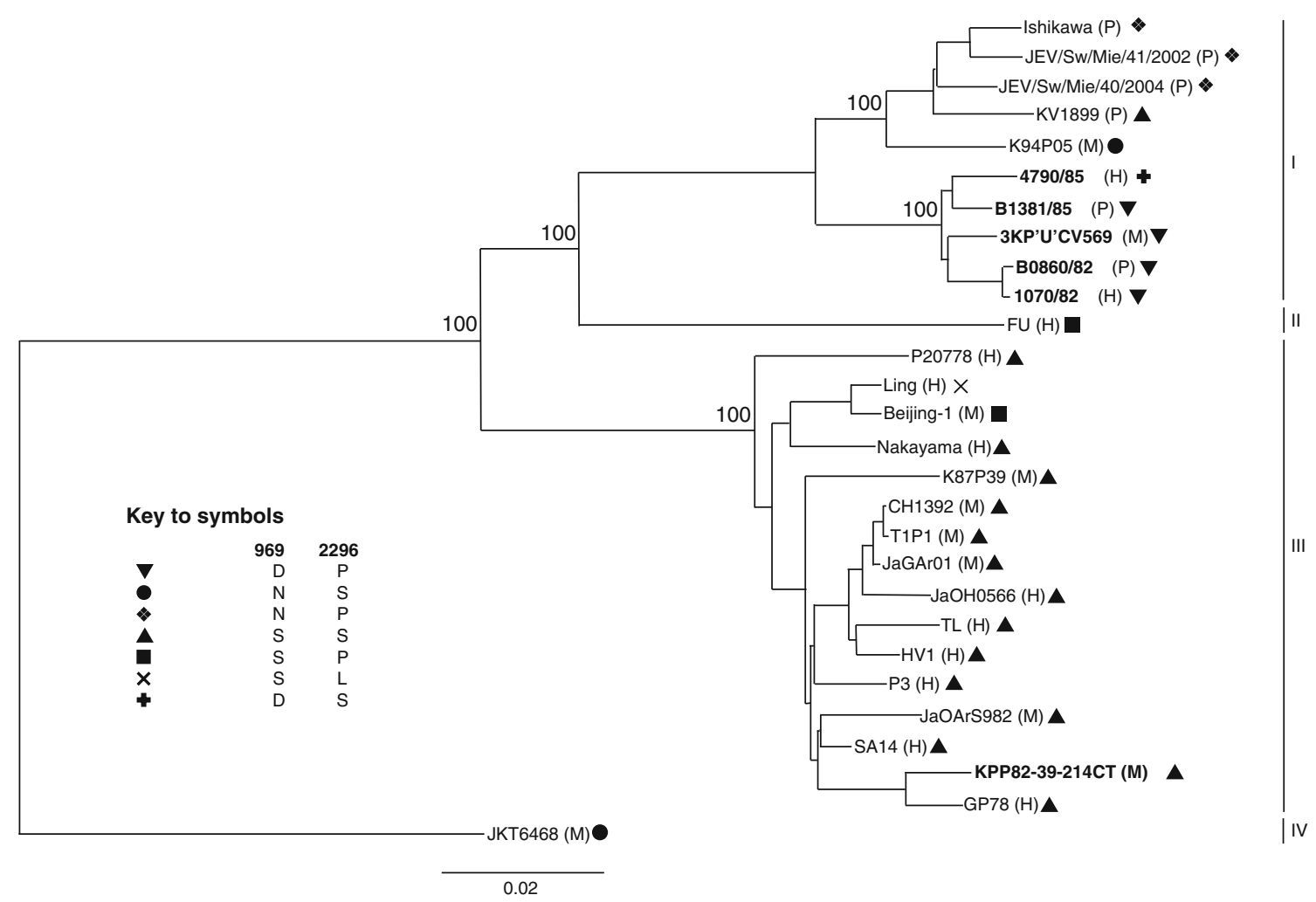

Fig. 1 Phylogenetic tree of complete genomes of 28 Japanese encephalitis virus isolates. The six isolates from KPP, Thailand, sequenced for this study are highlighted in bold text, and the host species is indicated after the strain names ( $\mathrm{H}$, human; $\mathrm{M}$, mosquito; $\mathrm{P}$,

existed for detectable recombination. As recombinant sequences can lead to aberrant results in phylogenetic analysis, Splits Tree analysis was performed to identify any potential recombinants. There was no evidence of discordant relationships among the six isolates from Thailand sequenced for this study. However, a net-like pattern at the node linking K94P05, a virus isolated from a mosquito in Korea in 1994, to the rest of the tree is typical of conflicting phylogenetic signals in the data that may be caused by recombination (Fig. 2).

Analyses using programs available within RDP3 (RDP, Genescan, Bootscan, MaxChi, Chimaera, SiScan and 3Seq) all suggested that K94P05 is a recombinant and that the strains closest to the likely major and minor parents were Ishikawa (a genotype 1 strain) and JaOArS982 (a genotype III strain), respectively. A similarity plot of the complete genome sequence of K94P05 compared with Ishikawa and JaOArS982 suggested that recombination had occurred in K94P05 between nucleotides 8822 and 9246, in the NS5 gene (Fig. 3). When NJ trees were generated using segments of the region on either side of the identified breakpoints, bootstrap support $(\mathrm{n}=1000)$ for K94P05 clustering with genotype I strains was $100 \%$ for nucleotide segments 1-8822 and 9247-10982, and for K94P05 clustering with pig). Amino acid combinations present at codons 996 and 2296 are indicated by symbols. Percent bootstrap values $(n=1000)$ of major nodes are indicated. The genotype IV isolate JKT6468 was used as an outgroup. Bar, 0.02 nucleotide substitutions per site

genotype III strains, it was $99 \%$ for the region $8823-9246$ (Fig. 4).

\section{Positive selection identified in NS1 and NS4B}

The ratio of $d N$ to $d S$ substitutions per nucleotide site was estimated from an alignment of 27 complete genomes (the putative recombinant, K94P05, was excluded from the analysis). The predominant selective pressure acting on the JEV genome was purifying (i.e., negative selection), reflected in a $d N / d S$ value of less than one. For example, in SLAC $(\mathrm{p}=0.1), 22 \%$ of codons were under negative selection pressure. Seven sites were identified as under positive selection by integrative analysis. Two of these sites, codon 969-972 (amino acid 174 of NS1) and codon 2296-2298 (amino acid 24 of NS4B) were identified as under positive selection pressure by FEL $(p$-value $<0.1$ ) and had p-values of $<0.3$ and $<0.2$, respectively, by SLAC (Table 3).

The different combinations of amino acids encoded at codons 969 and 2296 cluster according to genotype, i.e., they are phylogenetically informative (Fig. 1). The genotype III viruses (with the exception of Beijing and Ling) had serine at 969 and 2296. There was more variation 
Table 2 Amino acid changes among viruses isolated from a mosquito, human or pig during 1985 in Kamphaeng Phet Province, Thailand

\begin{tabular}{|c|c|c|c|c|c|c|c|c|c|c|c|c|c|c|c|}
\hline \multirow[t]{2}{*}{ Strain (species of origin) } & \multicolumn{4}{|c|}{ Capsid } & \multicolumn{3}{|c|}{ Envelope } & \multicolumn{2}{|l|}{ NS1 } & \multicolumn{2}{|c|}{ NS2A } & \multirow{2}{*}{$\begin{array}{l}\text { NS4B } \\
24\end{array}$} & \multicolumn{3}{|l|}{ NS5 } \\
\hline & 51 & 52 & 113 & 116 & 120 & 123 & 434 & 206 & 251 & 97 & 179 & & 108 & 830 & 889 \\
\hline $3 \mathrm{KP}^{\prime} \mathrm{U}^{\prime} \mathrm{CV} 569$ (Mosquito) & Ile & Thr & Met & Ala & Ser & Ser & Phe & Leu & Lys & Ala & Thr & Pro & Ala & Met & Ile \\
\hline B1381/85 (Pig) & Val & Ala & Val & Ala & Ser & Ser & Phe & Phe & Arg & Ala & Ile & Pro & Ala & Thr & Thr \\
\hline 4790/85 (Human) & Ile & Thr & Met & Val & Thr & Asn & Leu & Leu & Arg & Thr & Ile & Ser & Val & Met & Thr \\
\hline
\end{tabular}

Bold typeface indicates occurrence of a different amino acid

Fig. 2 Splits Tree analysis of complete genomes of 28 Japanese encephalitis virus isolates. The names of the six isolates from KPP, Thailand, are in italics, and the putative recombinant strain K94P05 is highlighted in bold text. Bar, 0.01 nucleotide substitutions per site

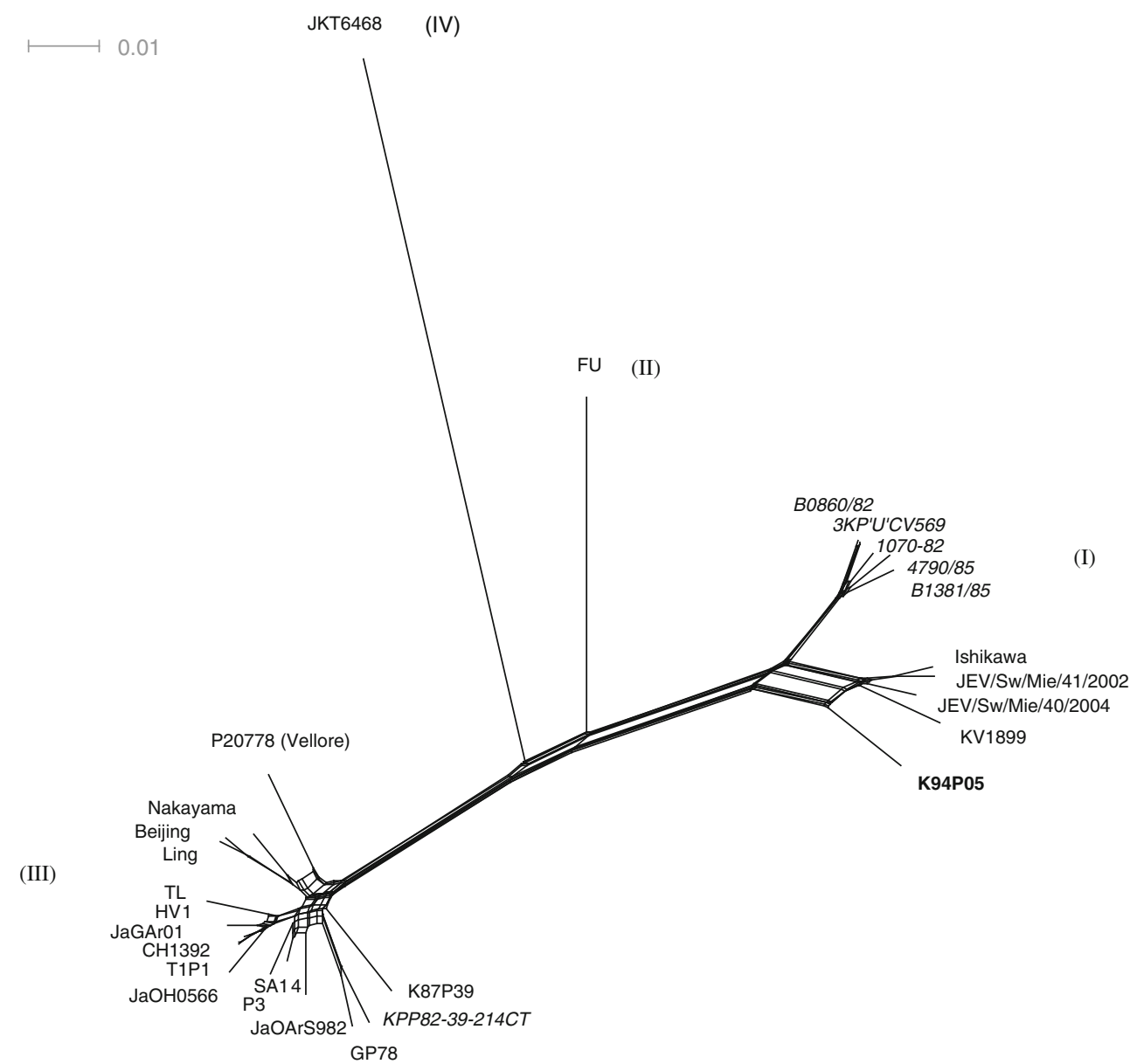

among the genotype I strains with the five genotype I KPP strains forming a separate sub-clade within the genotype. All five KPP strains had negatively charged aspartic acid at 969 (all other isolates had arginine or serine), and four of the isolates had proline at 2296, whereas the human 1985 isolate $(4790 / 85)$ had serine at 2296.

\section{Discussion}

In the present study, we demonstrated that, in Thailand, the conditions exist (that is, the co-circulation of genetically distinguishable strains of virus) for detectable recombination to occur in JEV. Co-circulation of genotypes I and III strains in the same country at the same time has been reported previously in China [35] and in Japan [15].

Analysis of available complete genome sequences of natural strains of JEV provided evidence of recombination in one of 28 isolates. RNA virus recombination was first detected in poliovirus [16] and has since been demonstrated in members of the family Flaviviridae. Recombinants were identified in all four serotypes of dengue virus [1, 3, 33, 37] and SLEV [33]. Recombination in the envelope protein has also been described previously for JEV [11, 33]. This is the first report of recombination detected in JEV from a complete genome analysis.

Viruses may be erroneously identified as recombinants [9], for example as a result of labeling errors in the 


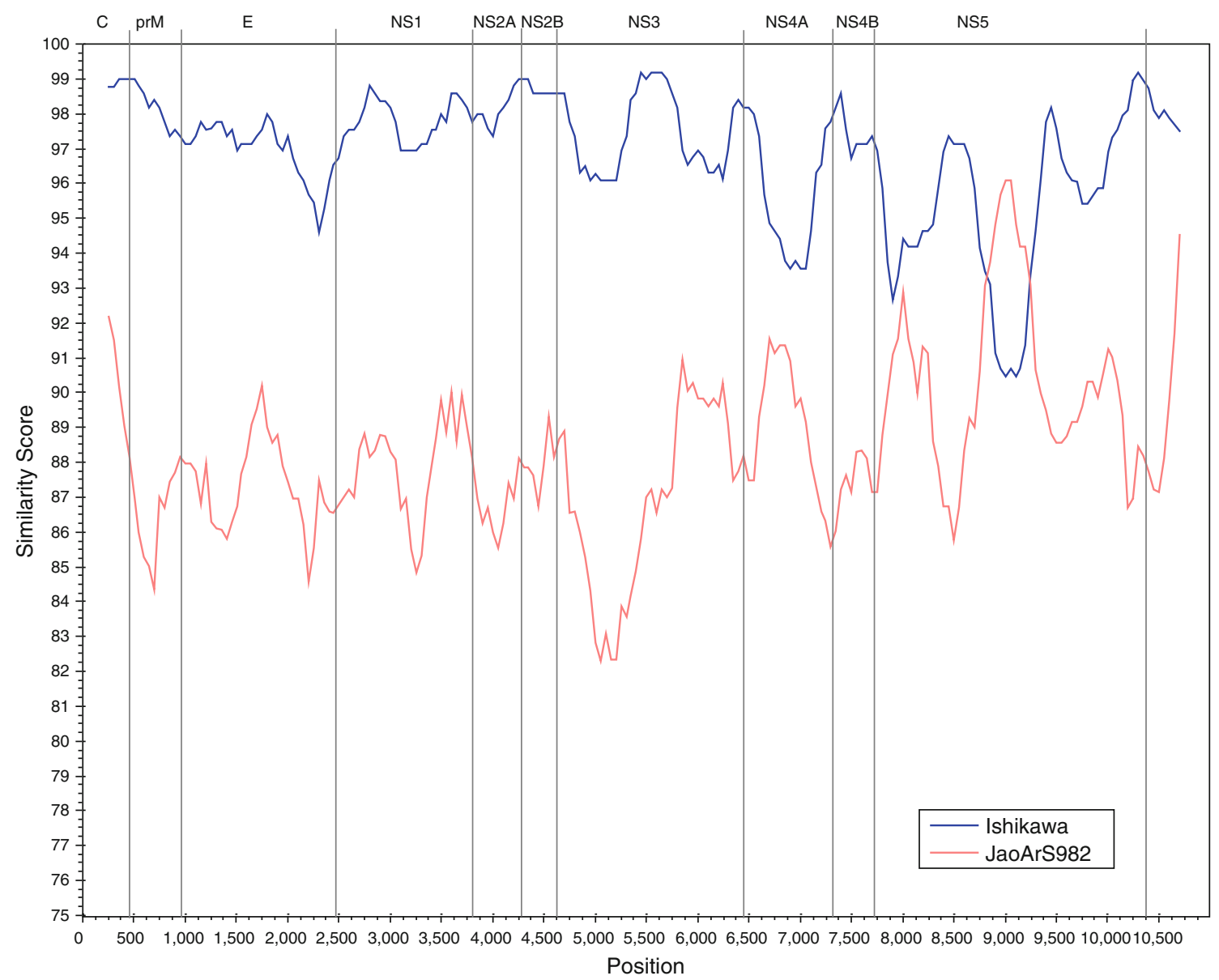

Fig. 3 Simplot comparison of complete genome sequences of K94P05, Ishikawa and JaOArS982. The x-axis indicates the nucleotide position, and the $\mathrm{y}$-axis, the percent nucleotide similarity

laboratory or if sequence is acquired from an uncloned virus. Unfortunately, the K94P05 strain identified as a putative recombinant in this study was not available for the presence of recombination to be confirmed by independent sequencing. The published sequence was reported to have been confirmed by an independent PCR amplification, and if discrepancies were found between the two sequence results, a third independent PCR amplification was performed to determine the sequence [24]. In their study of recombination in flaviviruses using $\mathrm{E}$ gene sequence data published in GenBank, Twiddy and Holmes (2003) identified 3 of 49 strains analyzed as recombinants. Interestingly, two of these were also isolated in Korea, in 1982 (K82P01) and 1991 (K91P55) [33]. Twiddy and Holmes (2003) report the 'parents' of the two putative recombinants from Korea as genotype I and II strains, but they assigned the viruses to genotypes differently to other authors [4, 30, 34]. Their genotypes I and II are equivalent to genotypes I and III, respectively, in the nomenclature of Chen et al. [4], which is the nomenclature adopted in this study. Further support for the occurrence of recombination between the sequence of the putative recombinant K94P05 and each parent, plotted at the midpoint of the window. The window size was $400 \mathrm{bp}$, and the increment was $50 \mathrm{bp}$

in JEV in nature comes from a study in which JEV recombinants were generated in vitro by co-infection of cells with two plaque-purified virus strains [6]. Recombination 'hot spots' of AU-rich sequences have been identified in other viruses with single-strand positive-sense genomic RNA [29]. Stretches of AU-rich sequence were identified on either side of the putative recombination breakpoints in the NS5 gene of K94P55 (unpublished data).

As a putative recombinant, the sequence of K94P55 was excluded from subsequent analyses for selection pressures. The strongest evidence for positive selection in the JEV genome was at the codon for amino acid 24 of NS4B (codon 2296). Of note was the finding that there is a nonconservative amino acid change in the Thai human isolate from 1985 (4790/85) at this position; the mosquito and pig isolates had proline, and the human isolate had serine. However, the majority of genotype III strains, including viruses isolated from mosquitoes and another genotype I strain (KV1899), also had serine at position 2296. The substitution in 4790/85 may nonetheless be significant-no other isolate had the same combination of D996 and S2296. 


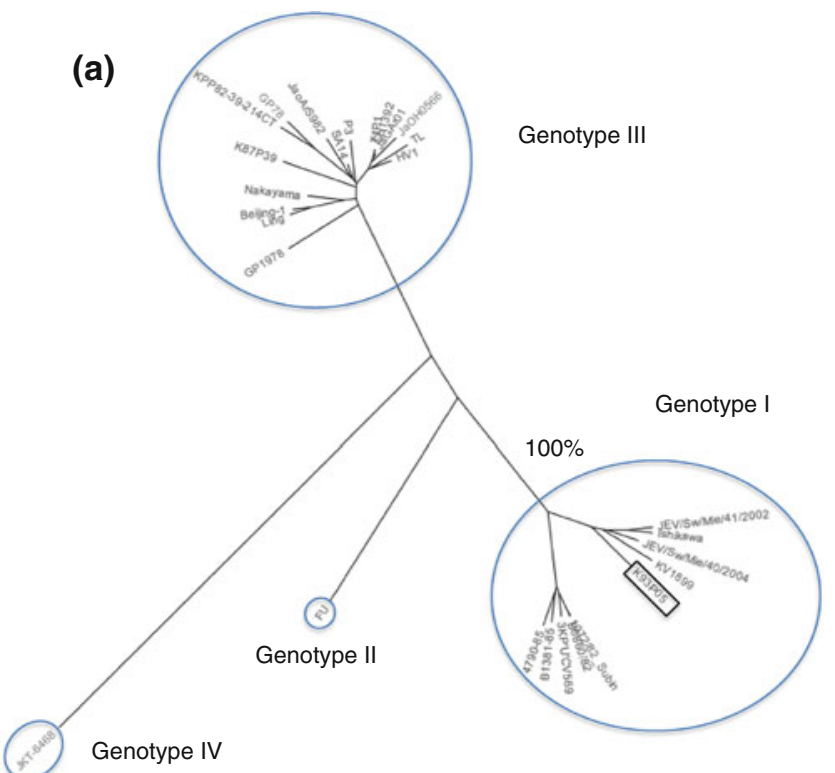

0.02

(c)

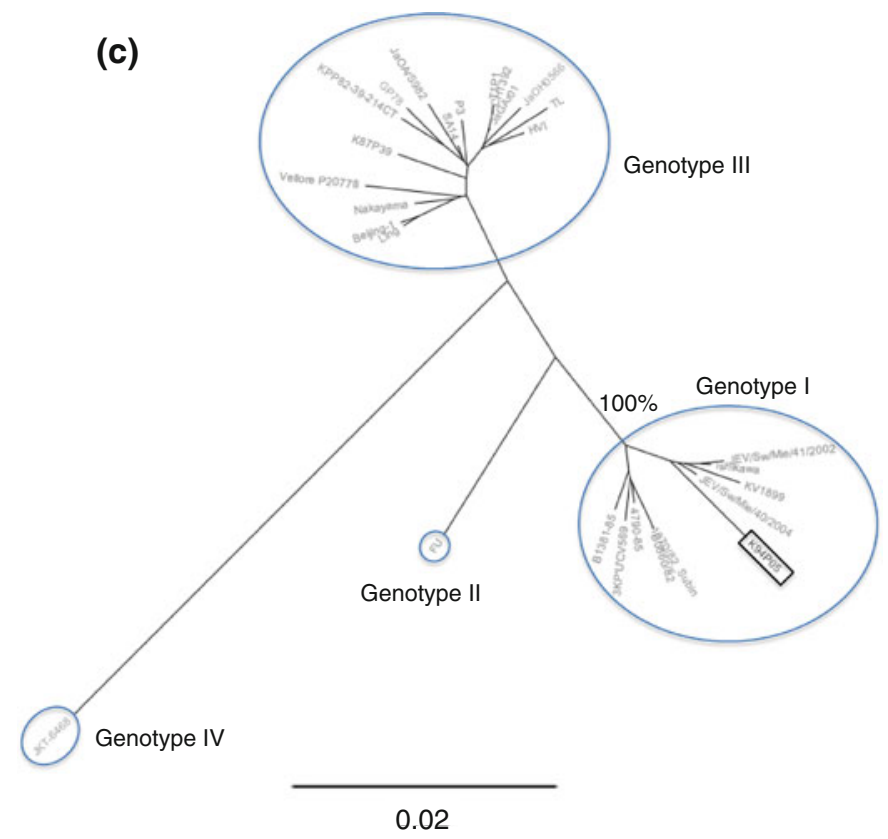

(b)

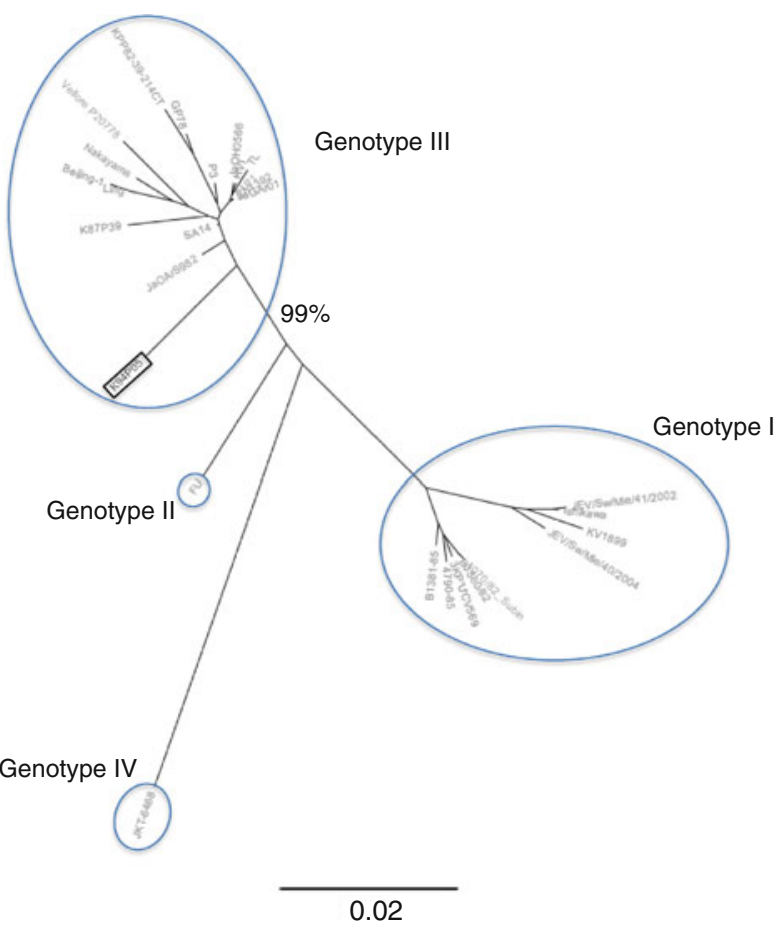

Fig. 4 Phylogenetic trees showing shifts in phylogenetic position of segments of K94P05 on either side of the putative breakpoints: nucleotides 1-8822 (a), 8823-9246 (b), and 9247-10,982 (c). Percent bootstrap support $(n=1000)$ for the putative recombinant strain

NS4B has been shown to play a role as an interferon (IFN) antagonist in dengue virus [22, 23] and WNV [10]. In light of these observations, examining the effects of substitution at codon 2296 on replication in IFN-competent versus deficient cells using an infectious clone may provide interesting data.
K94P05 (highlighted in a square text box) clustering with different genotypes is indicated. The trees are unrooted, and branch lengths are drawn to scale. The genotype IV isolate JKT6468 was used as an outgroup

A second site of positive selection was identified at amino acid 175 of the NS1 protein, within a cluster of negatively charged residues (169-KITEEDTDECD-179). Such clusters of residues are generally located on the surface of proteins. Substitution of an uncharged amino acid (e.g., asparagine or serine found in the majority of isolates) 
Table 3 Codons in the Japanese encephalitis virus genome identified as under positive selection pressure by at least one method of analysis

\begin{tabular}{|c|c|c|c|c|c|c|}
\hline \multirow[t]{2}{*}{ Codon } & \multicolumn{2}{|l|}{ SLAC } & \multicolumn{2}{|l|}{ FEL } & \multicolumn{2}{|l|}{ REL } \\
\hline & $\mathrm{dN}-\mathrm{dS}$ & p-value & $\mathrm{dN}-\mathrm{dS}$ & $\mathrm{p}$-value & $\mathrm{dN}-\mathrm{dS}$ & Bayes f \\
\hline 521 & 1.736 & 0.444 & 0.702 & 0.225 & -0.328 & 53.489 \\
\hline 969 & 3.275 & 0.250 & 2.636 & $0.045^{\mathrm{a}}$ & -0.310 & 66.601 \\
\hline 1152 & 1.709 & 0.459 & 0.957 & 0.121 & -0.194 & 104.610 \\
\hline 1180 & 1.703 & 0.462 & 0.884 & 0.132 & -0.199 & 100.202 \\
\hline 1335 & 1.736 & 0.444 & 0.767 & 0.209 & -0.320 & 56.468 \\
\hline 1611 & 2.563 & 0.311 & 1.429 & 0.171 & -0.362 & 51.256 \\
\hline 2296 & 4.528 & 0.122 & 2.407 & 0.081 & -0.358 & 52.501 \\
\hline
\end{tabular}

${ }^{a}$ Bold text indicates codon non-neutral at specified significance level ( $p<0.1$ for SLAC and FEL, Bayes factor $\geq 50$ for REL)

for a charged amino acid (e.g., aspartic acid found in the five genotype I KPP isolates) within this region could potentially interrupt protein-protein interactions. NS1 is required for viral replication [18], and high levels are produced during flavivirus infection, resulting in the production of specific antibodies [14, 17, 20]. It has also recently been shown to have a potential role in immunomodulation $[7,8,36]$.

In summary, using a bioinformatics approach, evidence of recombination in a JEV isolate from Korea was detected. Also, two regions of the JEV genome, in the NS1 and NS4B genes, that are under positive selection were identified. These may warrant further investigation.

Open Access This article is distributed under the terms of the Creative Commons Attribution Noncommercial License which permits any noncommercial use, distribution, and reproduction in any medium, provided the original author(s) and source are credited.

\section{References}

1. Aaskov J, Buzacott K, Field E, Lowry K, Berlioz-Arthaud A, Holmes EC (2007) Multiple recombinant dengue type 1 viruses in an isolate from a dengue patient. J Gen Virol 88:3334-3340

2. Chambers TJ, Hahn CS, Galler R, Rice CM (1990) Flavivirus genome organization, expression, and replication. Annu Rev Microbiol 44:649-688

3. Chen SP, Yu M, Jiang T, Deng YQ, Qin CF, Han JF, Qin ED (2008) Identification of a recombinant dengue virus type 1 with 3 recombination regions in natural populations in Guangdong province, China. Arch Virol 153:1175-1179

4. Chen WR, Rico-Hesse R, Tesh RB (1992) A new genotype of Japanese encephalitis virus from Indonesia. Am J Trop Med Hyg 47:61-69

5. Chenna R, Sugawara H, Koike T, Lopez R, Gibson TJ, Higgins DG, Thompson JD (2003) Multiple sequence alignment with the Clustal series of programs. Nucleic Acids Res 31:3497-3500

6. Chuang CK, Chen WJ (2009) Experimental evidence that RNA recombination occurs in the Japanese encephalitis virus. Virology 394:286-297
7. Chung KM, Liszewski MK, Nybakken G, Davis AE, Townsend RR, Fremont DH, Atkinson JP, Diamond MS (2006) West Nile virus nonstructural protein NS1 inhibits complement activation by binding the regulatory protein factor $\mathrm{H}$. Proc Natl Acad Sci USA 103:19111-19116

8. Chung KM, Thompson BS, Fremont DH, Diamond MS (2007) Antibody recognition of cell surface-associated NS1 triggers Fcgamma receptor-mediated phagocytosis and clearance of West Nile Virus-infected cells. J Virol 81:9551-9555

9. de Silva A, Messer W (2004) Arguments for live flavivirus vaccines. Lancet 364:500

10. Evans JD, Seeger C (2007) Differential effects of mutations in NS4B on West Nile virus replication and inhibition of interferon signaling. J Virol 81:11809-11816

11. Gould EA, Moss SR, Turner SL (2004) Evolution and dispersal of encephalitic flaviviruses. Arch Virol (Suppl) 18:65-84

12. Hanna JN, Ritchie SA, Phillips DA, Lee JM, Hills SL, van den Hurk AF, Pyke AT, Johansen CA, Mackenzie JS (1999) Japanese encephalitis in north Queensland, Australia, 1998. Med J Aust 170:533-536

13. Huson DH, Bryant D (2006) Application of phylogenetic networks in evolutionary studies. Mol Biol Evol 23:254-267

14. Konishi E, Pincus S, Fonseca BA, Shope RE, Paoletti E, Mason PW (1991) Comparison of protective immunity elicited by recombinant vaccinia viruses that synthesize E or NS1 of Japanese encephalitis virus. Virology 185:401-410

15. Kuwayama M, Ito M, Takao S, Shimazu Y, Fukuda S, Miyazaki K, Kurane I, Takasaki T (2005) Japanese encephalitis virus in meningitis patients, Japan. Emerg Infect Dis 11:471-473

16. Lai MM (1992) RNA recombination in animal and plant viruses. Microbiol Rev 56:61-79

17. Libraty DH, Young PR, Pickering D, Endy TP, Kalayanarooj S, Green S, Vaughn DW, Nisalak A, Ennis FA, Rothman AL (2002) High circulating levels of the dengue virus nonstructural protein NS1 early in dengue illness correlate with the development of dengue hemorrhagic fever. J Infect Dis 186:1165-1168

18. Lindenbach BD, Rice CM (1997) trans-Complementation of yellow fever virus NS1 reveals a role in early RNA replication. J Virol 71:9608-9617

19. Lole KS, Bollinger RC, Paranjape RS, Gadkari D, Kulkarni SS, Novak NG, Ingersoll R, Sheppard HW, Ray SC (1999) Fulllength human immunodeficiency virus type 1 genomes from subtype C-infected seroconverters in India, with evidence of intersubtype recombination. J Virol 73:152-160

20. Macdonald J, Tonry J, Hall RA, Williams B, Palacios G, Ashok MS, Jabado O, Clark D, Tesh RB, Briese T, Lipkin WI (2005) NS1 protein secretion during the acute phase of West Nile virus infection. J Virol 79:13924-13933

21. Martin DP, Williamson C, Posada D (2005) RDP2: recombination detection and analysis from sequence alignments. Bioinformatics (Oxford, England) 21:260-262

22. Munoz-Jordan JL, Sanchez-Burgos GG, Laurent-Rolle M, Garcia-Sastre A (2003) Inhibition of interferon signaling by dengue virus. Proc Natl Acad Sci USA 100:14333-14338

23. Munoz-Jordan JL, Laurent-Rolle M, Ashour J, Martinez-Sobrido L, Ashok M, Lipkin WI, Garcia-Sastre A (2005) Inhibition of alpha/beta interferon signaling by the NS4B protein of flaviviruses. J Virol 79:8004-8013

24. Nam JH, Chae SL, Won SY, Kim EJ, Yoon KS, Kim BI, Jeong YS, Cho HW (2001) Short report: genetic heterogeneity of Japanese encephalitis virus assessed via analysis of the full-length genome sequence of a Korean isolate. Am J Trop Med Hyg 65:388-392

25. Olsthoorn RC, Bol JF (2001) Sequence comparison and secondary structure analysis of the $3^{\prime}$ noncoding region of flavivirus genomes reveals multiple pseudoknots. RNA 7:1370-1377 
26. Posada D, Crandall KA (1998) MODELTEST: testing the model of DNA substitution. Bioinformatics (Oxford, England) 14:817-818

27. Pyke AT, Williams DT, Nisbet DJ, van den Hurk AF, Taylor CT, Johansen CA, Macdonald J, Hall RA, Simmons RJ, Mason RJ, Lee JM, Ritchie SA, Smith GA, Mackenzie JS (2001) The appearance of a second genotype of Japanese encephalitis virus in the Australasian region. Am J Trop Med Hyg 65:747-753

28. Rambaut A (2006) FigTree. Institute of Evolutionary Biology, University of Edinburgh, Edinburgh

29. Shapka N, Nagy PD (2004) The AU-rich RNA recombination hot spot sequence of Brome mosaic virus is functional in tombusviruses: implications for the mechanism of RNA recombination. J Virol 78:2288-2300

30. Solomon T, Ni H, Beasley DW, Ekkelenkamp M, Cardosa MJ, Barrett AD (2003) Origin and evolution of Japanese encephalitis virus in southeast Asia. J Virol 77:3091-3098

31. Solomon T, Winter PM (2004) Neurovirulence and host factors in flavivirus encephalitis-evidence from clinical epidemiology. Arch Virol 18(Suppl):161-170

32. Swofford DL (1998) PAUP*: phylogenetic analysis using parsimony (and other methods). Sinauer Associates, Sunderland
33. Twiddy SS, Holmes EC (2003) The extent of homologous recombination in members of the genus Flavivirus. J Gen Virol 84:429-440

34. Uchil PD, Satchidanandam V (2001) Phylogenetic analysis of Japanese encephalitis virus: envelope gene based analysis reveals a fifth genotype, geographic clustering, and multiple introductions of the virus into the Indian subcontinent. Am J Trop Med Hyg 65:242-251

35. Wang LH, Fu SH, Wang HY, Liang XF, Cheng JX, Jing HM, Cai GL, Li XW, Ze WY, Lv XJ, Wang HQ, Zhang DL, Feng Y, Yin ZD, Sun XH, Shui TJ, Li MH, Li YX, Liang GD (2007) Japanese encephalitis outbreak, Yuncheng, China, 2006. Emerg Infect Dis 13:1123-1125

36. Wilson JR, de Sessions PF, Leon MA, Scholle F (2008) West Nile virus nonstructural protein 1 inhibits TLR3 signal transduction. J Virol 82:8262-8271

37. Worobey M, Rambaut A, Holmes EC (1999) Widespread intraserotype recombination in natural populations of dengue virus. Proc Natl Acad Sci USA 96:7352-7357 